\title{
Effects of Retinoic Acid on the Differentiation of THP-1 Cell Lines Containing Aneuploid or Diploid Chromosomes
}

\author{
Fuminori Hyodoh \\ Department of Pathology, Kawasaki Medical School, Kurashiki 701-01, Japan
}

\begin{abstract}
The effects of retinoic acid on the differentiation of human monocytic leukemia cell lines containing aneuploid (THP-1-Cs5) or diploid chromosomes (THP-1-R) were studied and compared. The induction of cell adhesion to a substratum, phagocytosis of sheep red blood cells (SRBC) or IgG-coated SRBC, pinocytosis of dextran sulfate, and NBT dye reduction by the cells were examined. The occurence of these processes was much greater in RA-treated THP-1-Cs 5 cells than in RA-treated THP-1-R cells. Of all these functional activities, the most remarkable differences between the two cell types were seen for cell adhesion and phagocytosis of SRBC.

Morphological changes in RA-treated THP-1-Cs5 cells were observed by light and electron microscopy. RA-treated THP-1-Cs5 cells had a moderatelydeveloped Golgi apparatus, and abundant lysosomes, mitochondria and lipid droplets in the cytoplasm. Among various retinoids examined, RA was the strongest inducer of the differentiation of the THP-1-Cs5 cells into mature cells. These findings suggest that THP-1-Cs5 cells which contain aneuploid chromosomes are more efficiently functionally differentiated by RA than are THP-1-R cells.
\end{abstract}

The mononuclear phagocytes (monocytes, macrophages) play important roles in immunity and the host defense mechanism. The well known fundamental and functional characteristics of mononuclear phagocytes are their ability to adhere, phagocytose and pinocytose $(8,38)$.

It is therefore important to examine the extent of the functional conversion of malignant leukemic cells into normally functioning ones after the leukemic cells are exposed to differentiation inducing agents. The U-937 cell line (35) is a histiocytic lymphoma cell line and THP-1 (36) is a monocytic leukemia cell line. These two cell lines are known to possess monocytic characteristics. Recently, it has been demonstrated that U-937 cells are induced to differentiate into mature monocytesmacrophages by TPA, supernatant from mixed leukocyte culture, interferon $\gamma$, and retinoic acid (RA) $(10,20,21,26)$. THP-1 cells can also be induced to differentiate into mature cells by TPA, mezerein and RA $(6,11,37)$.

RA is known as one of the strongest differentiation-inducing agents $(2,13,31)$. In the present investigation, we undertook to compare the responses of two THP-1

Abbreviations used: RA, retinoic acid; SRBC, sheep red blood cells; IgG, immunoglobulin G; HRP, horseradish peroxidase; TEM, transmission electron microscopy; SEM, scanning electron microscopy; ANAE, a-naphthyl acetate esterase; NADE, naphthol AS-D chloroacetate esterase; ANBE, $a$-naphthyl butyrate esterase; RER, rough endoplasmic reticulum. 
cells to RA. THP-1-Cs5 cells possess an aneuploid karyotype with more than 60 chromosomes, while THP-1-R cells maintain modal diploid chromosomes. The ability of the inducer to induce cell adhesion to a substratum, phagocytosis of SRBC and IgG-coated SRBC, pinocytosis of dextran sulfate, and NBT reduction in the two THP-1 cells was studied and the results for the two cell lines were compared. In addition, the effects of several other retinoids on THP-1-Cs5 cells were also studied. A preliminary report of a part of these results has previously been given (15).

\section{MATERIALS AND METHODS}

Cells and cultures. Two THP-1 cell lines, established from a human monocytic leukemia by Tsuchiya (36), were used. One of them, the THP-1-Cs5 cell line containing aneuploid chromosomes, cloned by Mimura and others was generously provided by Dr. Mimura (Asahi Chemical Industry Co. Ltd.). The other THP-1 line, the THP-1-R cell line having diploid chromosomes, was generously provided by Dr. Minegishi (Tohoku University, School of Medicine, Japan). These cells were maintained in a suspension culture in RPMI 1640 medium (Nissui Co., Tokyo) supplemented with $10 \%$ heat inactivated fetal bovine serum and $150 \mu \mathrm{g} / \mathrm{ml}$ of Kanamycin. They were incubated at $37^{\circ} \mathrm{C}$ in a humidified atomosphere containing $5 \% \mathrm{CO}_{2}$ in air $\left(\mathrm{CO}_{2}\right.$ incubator, Type B-1001, R.K.I. Co. Ltd.).

Chemicals. Retinoic acid (all trans: Vitamin A acid), retinol (all trans: Vitamin A alcohol), retinal (all trans: Vitamin A aldehyde) and retinyl acetate (all trans: Vitamin A acetate) were obtained from Sigma Chemicals Co., St. Louis. Mo. These chemicals and phorbol myristate acetate (Consolidated Midland Corporation, Brewster, N.Y. and Sigma) were stored at $-30^{\circ} \mathrm{C}$. All retinoids were dissolved in $99.5 \%$ ethanol at a concentration of $10^{-2}$ M. Retinoid solutions were diluted with $99.5 \%$ ethanol and then with culture medium to achieve the required concentrations. The final ethanol concentrations were no higher than $0.4 \%$. All manipulations were performed in subdued light.

Assay of the properties of differentiated cells. THP- 1 cells $\left(2 \times 10^{5}\right.$ cells $\left./ \mathrm{ml}\right)$ were suspended in growth medium containing different concentrations of the differentiation inducing agents, and incubated for 6 days in a $35 \mathrm{~mm}$ culture dish (Falcon Plastics, U.S.A.). The cells were harvested every 2 days. An aliquot of the cell suspension was stained with trypan blue for viable cell density counting, while the remaining cells were examined for certain acquired characteristics as follows.

Adherent activity. Cells $\left(2 \times 10^{5} / \mathrm{ml}\right)$ were treated with agents at various concentrations and for various lengths of time. Then, the culture vessels were agitated manually to remove non-adherent cells and weakly adhered cells. The cells were stained with $0.1 \%$ crystal violet in $0.1 \mathrm{M}$ citric acid, and then the number of adherent and non-adherent cells were counted in a hemocytometer. In one experiment, the effects of fresh RA free medium or fresh medium containing horseradish peroxidase (HRP, $1 \mathrm{mg} / \mathrm{ml}$ ) on adhesion and the spreading capacities of the cells which had been incubated in the presence or absence of RA were investigated. RA-treated or non-treated cells were incubated with medium in the presence or absence of peroxidase for 1 to $2 \mathrm{~h}$. Thereafter, the percentage of adherent cells was determined as mentioned above. Spreading capacity was observed using a phase contrast microscope.

Phagocytosis of SRBC and IgG-coated SRBC. Phagocytosis of SRBC and IgG-coated SRBC by THP-1 cells was assayed as reported previously (16, 37). SRBC (Nippon Bio-Test Lab. Inc.) were sensitized with 7S-anti SRBC rabbit serum (M.B.L.), and $5 \times 10^{7}$ cells of IgG-coated SRBC or SRBC were added to $5 \times 10^{5}$ cells of THP-1 cells in $\mathrm{Mg}^{++}$and $\mathrm{Ca}^{++}$ free PBS. The mixture was centrifuged at $600 \mathrm{rpm}$ for $5 \mathrm{~min}$ (KC-70, KUBOTA) and 
incubated at $37^{\circ} \mathrm{C}$ for $25 \mathrm{~min}$. After incubation, some pellets were thoroughly resuspended in the growth medium and kept cold on ice. The cell suspensions were stained with trypan blue, and the viable cells which had Fc receptors were counted. Cells with more than 3 IgGcoated SRBC attached were counted as Fc receptor positive cells. Other pellets were thoroughly resuspended in $1 \mathrm{ml}$ of the growth medium and incubated for $2 \mathrm{~h}$ at $37^{\circ} \mathrm{C}$ in order to examine the capacity of the THP-1 cells to phagocytose the attached SRBC. At the end of the incubation, $1 \mathrm{ml}$ of a $0.14 \mathrm{M}$ solution of $\mathrm{NH}_{4} \mathrm{Cl}$ was added to lyse attached, non-internalized SRBC. Then, $5 \mathrm{mls}$ of the growth medium were added and the cells were centrifuged at $900 \mathrm{rpm}$ for $5 \mathrm{~min}$. Thereafter, cells were centrifuged onto slides with a Tomy apparatus (Tominaga Works Ltd.), fixed with methanol and stained with Giemsa. The percentage of phagocytes and the mean number of SRBC ingested per 100 phagocytes or by each phagocyte were determined. At least 300 cells were scored in each sample.

Pinocytosis. The pinocytic activity of the cells was studied by using horseradish peroxidase (HRP, type II, Sigma) and dextran sulfate (M.W. 500,000; Nakarai Chemicals, Japan) as previously reported $(23,32,38)$.

To study the pinocytosis of HRP, RA-treated cells and non-treated cells were washed with RA-free growth medium and about $5 \times 10^{5}$ cells $/ \mathrm{ml}$ were exposed to $1 \mathrm{mg} / \mathrm{ml}$ of $\mathrm{HRP}$ in the growth medium for 30-120 min. Thereafter the cells were washed twice in the growth medium and twice in phosphate buffer. Then they were fixed for 5-10 min at room temperature in $2.5 \%$ glutaraldehyde in $0.1 \mathrm{M}$ sodium cacodylate buffer, $\mathrm{pH}$ 7.4. The fixative was removed with three washes of the buffer, and the HRP was cytochemically localized by incubating the sample for $20 \mathrm{~min}$ at room temperature in the diaminobenzidine- and $\mathrm{H}_{2} \mathrm{O}_{2}$-containing buffer described by Graham and Karnovsky (9). The ultrastructural localization of HRP was investigated as previously reported $(9,32)$.

To study the pinocytosis of dextran sulfate, the cells were incubated in a growth medium containing $100 \mu \mathrm{g} / \mathrm{ml}$ of dextran sulfate for 24 to $48 \mathrm{~h}$. After washing with PBS, samples were centrifuged at $600 \mathrm{rpm}$ for $5 \mathrm{~min}$ in a Tomy apparatus onto glass slides, fixed with methanol, and stained with either toluidine blue $(1 \%$ in $30 \%$ methanol) for $4 \mathrm{~min}$, or with $2.5 \%$ Giemsa for $30 \mathrm{~min}$, as reported previously (38).

NBT reduction. NBT reduction was assayed as reported previously (4). After Giemsa staining, the percentage of cells containing strong intracellular blue-black formazan deposits was determined after counting the labeled and unlabeled cells under a light microscope.

Morphological examinations. The morphological changes in THP-1 cells induced by RA were examined using light and electron microscopy. For light microscopy, cells were centrifuged onto slides using a Tomy apparatus and fixed with methanol followed by Giemsa staining.

For transmission electron microscopy (TEM), untreated control and RA-treated THP-1 cells were fixed in $2.5 \%$ glutaraldehyde for $2 \mathrm{~h}$ at $4{ }^{\circ} \mathrm{C}$, followed by $1 \% \mathrm{OsO}_{4}$ for $1 \mathrm{~h}$ at $4^{\circ} \mathrm{C}$. They were dehydrated through an ethanol series and embedded in epoxy resin (19). Ultrathin sections were stained with uranyl acetate and lead citrate (28), and examined with a Hitachi HU-12A electron microscope.

For scanning electron microscopy (SEM), specimens were fixed in $2 \%$ glutaraldehyde for $1 \mathrm{~h}$, postfixed in $1 \% \mathrm{OsO}_{4}$ for $1 \mathrm{~h}$, dehydrated through an ethanol series, and dried with a critical point dryer (Hitachi HCP-1). The samples were coated with AU-Pd and examined with a Hitachi HHS-2R electron microscope.

Histochemical methods. $\alpha$-naphthyl acetate esterase (ANAE) and naphthol AS-D chloroacetate esterase (NADE) were stained by the method of Yam et al. (40), peroxidase by the method of Graham and Karnovsky (9) or Roels et al. (29), $\alpha$-naphthyl butyrate ester- 
ase (ANBE) by that of Li et al. (18) and Willcox et al. (39), and acid phosphatase by that of Barka and Anderson (1).

Chromosomal analysis. Cells for chromosomal analysis were collected after treatment with colchicine for $2 \mathrm{~h}$. The preparations were treated with $0.075 \mathrm{M}$ potassium chloride for $8 \mathrm{~min}$, fixed with methanol/acetic acid $(3: 1)$, flame-dried, and stained with Giemsa. Fifty metaphase cells were studied.

\section{RESULTS}

Chromosome analysis of THP-1-Cs5 and THP-1-R cells. The THP-1-Cs5 cells had a near tetraploid chromosome number distribution ranging from 62 to 97 . In contrast, THP-1-R cells possessed a modal diploid chromosome number as shown in Fig. 1. The cells with diploid chromosomes made up approximately $50 \%$ of all the cells checked.

Effects of RA on the growth of THP-1-Cs5 and THP-1-R cells. Growth of THP-1Cs5 and THP-1-R cells was inhibited after the addition of RA. When the THP-1-Cs5

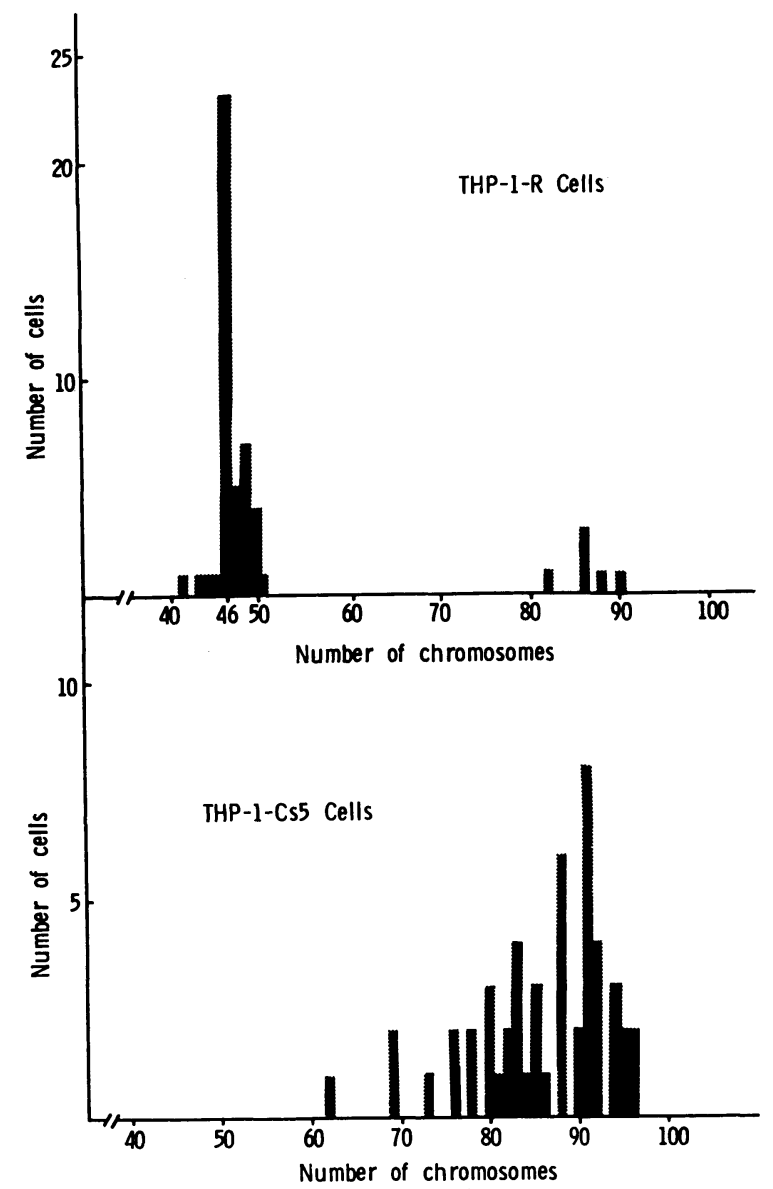

Fig. 1. The distribution of chromosome numbers in THP-1-Cs5 and THP-1-R cells. 
cells were cultured with $10^{-6}$ to $10^{-5} \mathrm{M}$ RA, cell growth nearly ceased in 2 days (Fig. 2). However, more than $80 \%$ of the cells were viable after 4 days. THP-1-R was more sensitive to RA than THP-1-Cs5. After 4 days of incubation, $10^{-5} \mathrm{M}$ RA-treated THP-1-Cs5 cells showed almost the same amount of growth inhibition as $10^{-6} \mathrm{M}$ RA-treated THP-1-R cells. After treatment with $10^{-6}$ to $10^{-5} \mathrm{M}$ RA for 6 days, there were many dead cells in the THP-1-R culture; the number of cells remaining in the culture exposed to $10^{-6}$ and $10^{-5} \mathrm{M}$ RA on day 6 was $41.6 \%$ and $37.7 \%$ respectively of the number of cells on day 4.

Morphological changes in THP-1-Cs5 cells induced by RA. Untreated THP-1-Cs5 cells stained with Giemsa appeared as round or somewhat spindle shaped immature cells. The cells had a moderate amount of basophilic cytoplasm which contained a few vacuoles. The cells showed a moderately high nuclear to cytoplasmic ratio, and their nuclei had an indented and irregular shape with 2 to 4 distinct nucleoli (Fig. 3a). Untreated THP-1-R cells showed a similar morphological appearance to untreated THP-1-Cs5 cells. After 4 days of treatment with $10^{-5} \mathrm{M}$ RA, nuclei had a more irregular shape and some of the cells had lobulated nuclei. Nucleoli were present, but less prominent in RA-treated cells than in untreated cells. The cytoplasm became less basophilic and the nuclear-cytoplasmic ratio decreased. There were many vacuoles in the cytoplasm (Fig. 3b). Morphological changes of RA-treated THP-1-R cells were less prominent than those of RA-treated THP-1-Cs5 cells.

Untreated cells were seen by TEM to contain a moderately abundant amount of ribosomes and polysomes in the cytoplasm. The cells also contained ill developed rough endoplasmic reticula (RER), a small number of mitochondria and a few lysosomal structures as shown in Fig. 4A. Fig. 4C demonstrates the ultrastructural changes that occur in the cells after 4 days of treatment with RA. The cell shows moderately-developed Golgi apparatus structures and an increase in the number of

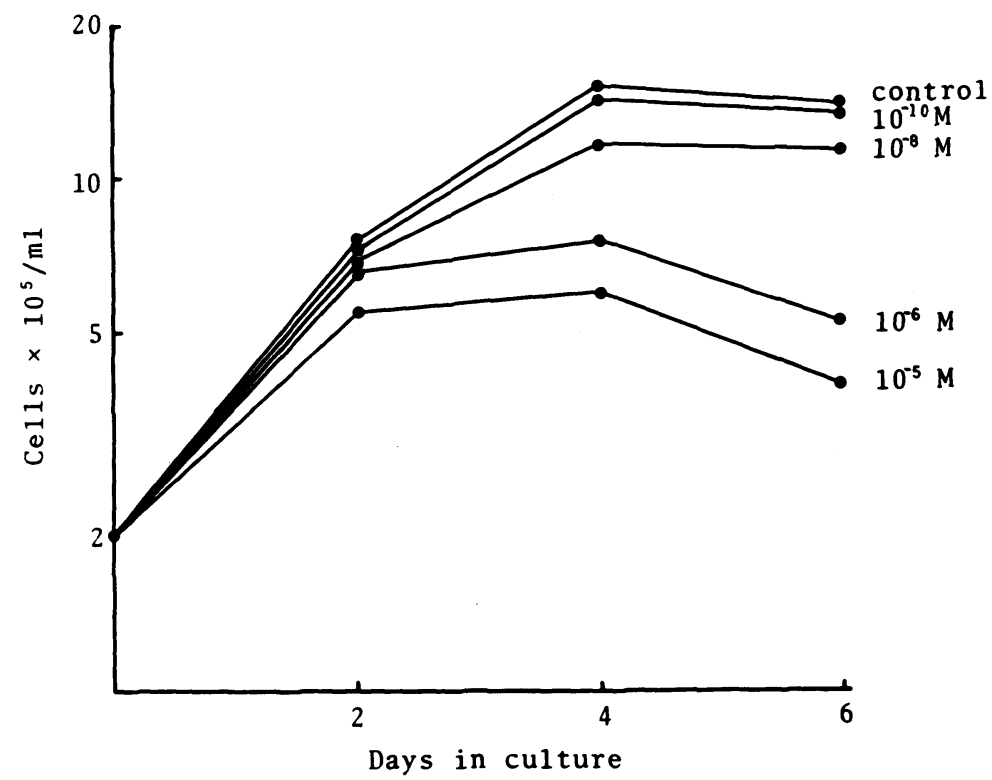

Fig. 2. Effects of various concentrations $\left(10^{-10} \mathrm{M}\right.$ to $\left.10^{-5} \mathrm{M}\right)$ of retinoic acid on the growth of THP-1-Cs5 cells. 

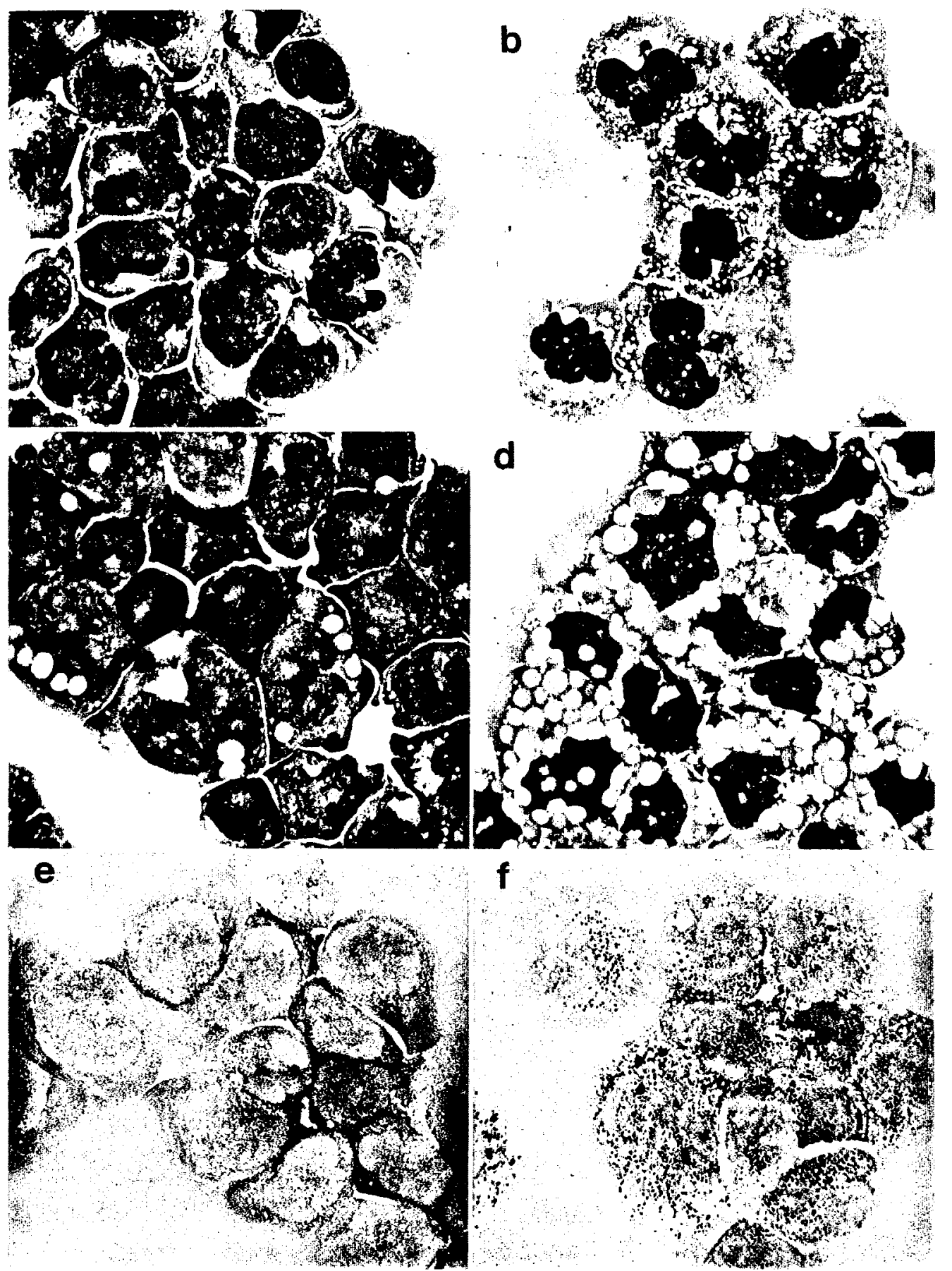

$f$

Fig. 3. 

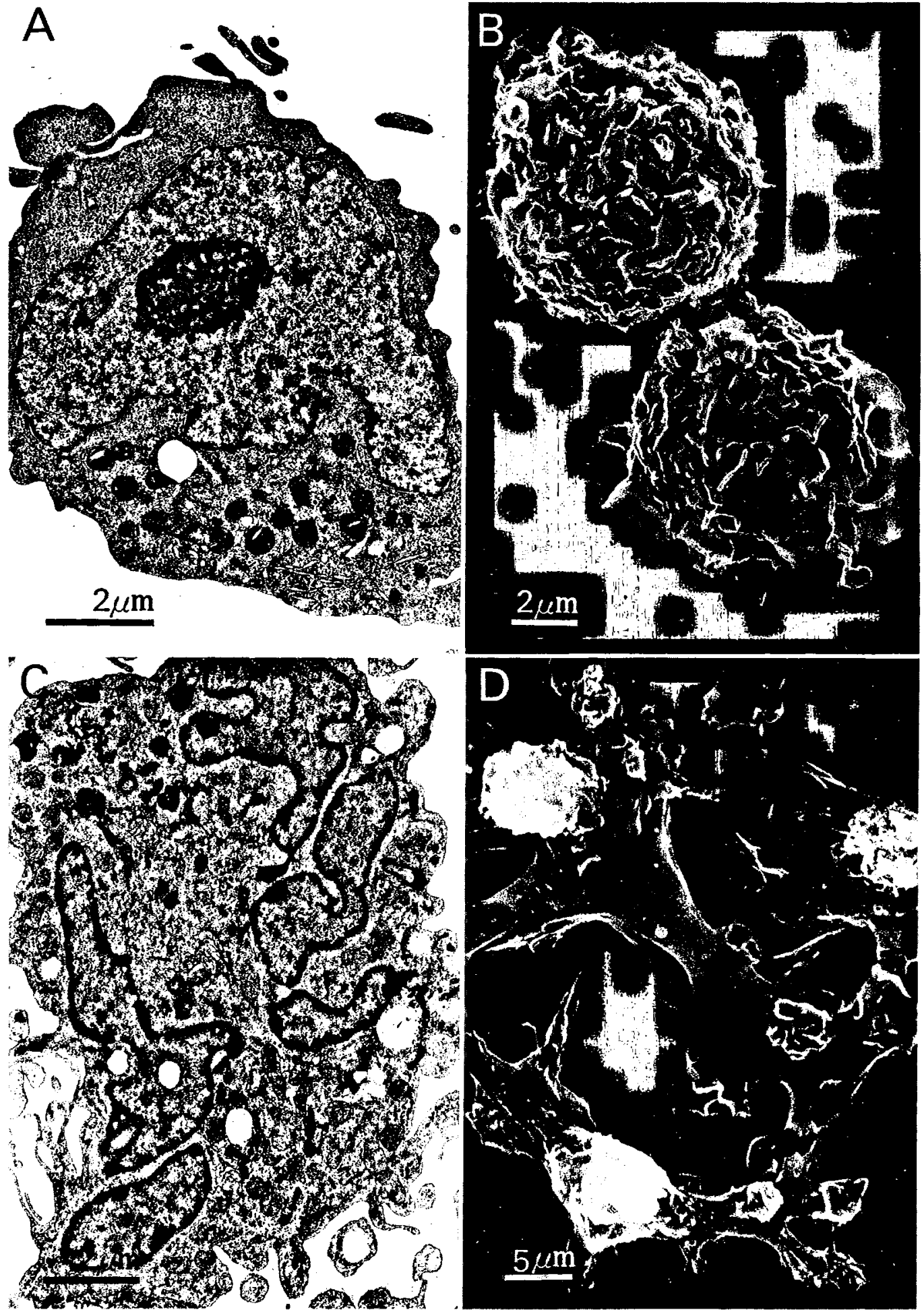

Fig. 4. 
mitochondria and pinocytic vesicles as well as a remarkable increase in the number of lysosomes. No bundles of intermediate filaments were observed near the nuclei in either RA-treated cells or untreated cells.

SEM showed that RA-treated cells adhered to the substrate in a wide variety of shapes. The surface ultrastructure of the cells was moderately smooth (Fig. 4D).

Effects of RA on the histochemical activities of THP-1-Cs5 cells and THP-1-R cells. The studies of the histochemical activities showed that both THP-1-Cs5 and THP-1-R cells were strongly positive for ANBE and ANAE in the presence or absence of RA. The staining completely disappeared when $0.04 \mathrm{M}$ sodium fluoride was added. Untreated cells in both cell lines were weakly positive for NADE and acid phosphatase, while RA-treated THP-1-Cs5 cells were strongly positive for acid phosphatase. No peroxidase activity was found in almost all the THP-1-Cs5 cells and THP-1-R cells, although a small number of cells $(<0.1 \%)$ had a weak peroxidase activity. Some cells among other THP-1-R cells which were generously given to us by Dr. Tsuchiya were also positive for peroxidase activity $(<1 \%)$.

Effects of $R A$ on the adhesion of THP-1-Cs5 and THP-1-R cells. As shown in Fig. 5a and Table 1, untreated THP-1-Cs5 and THP-1-R cells showed a minimal amount of adhesion. The treated THP-1-R cells, in most cases, could not acquire the ability, whereas THP-1-Cs5 cells became quite adhesive in the presence of RA. Maximal induction of adhesiveness occurred at a RA concentration of $10^{-5} \mathrm{M}$. The acquired capacity to adhere and spread increased when RA-treated cells were reincubated with RA-free fresh growth medium (Table 1, Fig. 5d-e). After a $2 \mathrm{~h}$ incubation in RA-free medium, adherent and spreading cells appeared in a wide variety of shapes. However, most of the spreading cells were of a fusiform type, often with processes.

Furthermore, as shown in Table 1 and Fig. 5f, most of the adherent cells were completely flat $1 \mathrm{~h}$ after the addition of $1 \mathrm{mg} / \mathrm{ml} \mathrm{HRP}$. The majority of the spreading cells showed a rounded, flattened appearance and had no processes. In contrast, RA treated THP-1-R cells did not acquire the ability to spread in the presence of fresh growth medium or after exposure to HRP at all (Table 1). After exposure to $10^{-7} \mathrm{M}$ RA for 4 days, THP-1-R cells still could not spread.

Effects of RA on the phagocytosis of IgG-coated SRBC and uncoated SRBC by THP-1-Cs5 and THP-1-R cells. More than $80 \%$ of both THP-1-Cs5 and THP-1-R cells were confirmed to possess Fc receptors. There was a slight difference between

Fig. 3. Light microscopical images of untreated and RA-treated THP-1-Cs5 cells. $\quad \times 600$

a: Untreated cells on day 2. Giemsa stain.

b: RA-treated $\left(10^{-5} \mathrm{M}\right)$ cells on day 4 . Giemsa stain.

c: Phagocytosis of IgG-coated SRBC by untreated cells on day 2. Giemsa stain.

d: Phagocytosis of IgG-coated SRBC by RA-treated cells on day 4. Giemsa stain.

e: Pinocytosis of dextran sulfate $(100 \mu \mathrm{g} / \mathrm{ml})$ by untreated cells on day 4 . Toluidine blue stain.

$\mathrm{f}$ : Pinocytosis of dextran sulfate $(100 \mu \mathrm{g} / \mathrm{ml})$ by RA-treated cells on day 4 . Toluidine blue stain.

Fig. 4. Ultrastructural appearance of THP-1-Cs5 cells.

A: An untreated cell on day 2 observed with TEM.

B: Untreated cells observed with SEM.

C: A cell treated with $10^{-5} \mathrm{M}$ RA for 4 days observed with TEM. Remarkable nuclear lobulation, many lysosomal particles and a number of mitochondria were seen in the cytoplasm.

D: Cells treated with $10^{-5} \mathrm{M}$ RA for 4 days observed with SEM. Three cells with moderately smooth surface structures are adhered to the glass substratum. 
TABLE 1. ADHERENCE OF THP-1-Cs5 AND THP-1-R CELlS AFTER TREATMENT WITH RA

Cells were treated with or without RA at the concentrations indicated for 2 or 4 days, followed by incubation with RA-free fresh growth medium or fresh growth medium containing $1 \mathrm{mg} / \mathrm{ml}$ of peroxidase for $2 \mathrm{~h}$. Each value represents the mean \pm S.E. of 4 repeat experiments.

\begin{tabular}{|c|c|c|c|c|c|}
\hline \multirow{2}{*}{$\begin{array}{c}\text { Incubation } \\
\text { time } \\
\text { (days) }\end{array}$} & \multirow{2}{*}{$\begin{array}{l}\mathrm{RA} \\
(\mathrm{M})\end{array}$} & \multicolumn{2}{|c|}{ THP-1-Cs5 } & \multicolumn{2}{|c|}{ THP-1-R } \\
\hline & & $\begin{array}{c}\text { Adherence } \\
(\%)\end{array}$ & Spreading a & $\begin{array}{c}\text { Adherence } \\
(\%)\end{array}$ & Spreading \\
\hline \multirow[t]{4}{*}{2} & 0 & $<1$ & - & $<1$ & - \\
\hline & $10^{-8}$ & $<1$ & - & $<1$ & - \\
\hline & $10^{-6}$ & $19.7 \pm 3.0$ & + & $<1$ & - \\
\hline & $10^{-5}$ & $35.6 \pm 2.2$ & + & $<1$ & - \\
\hline \multirow[t]{12}{*}{4} & 0 & $<1$ & - & $<1$ & - \\
\hline & Medium & $<1$ & - & $<1$ & - \\
\hline & POase & $<1$ & - & $<1$ & - \\
\hline & $10^{-8}$ & $<3$ & - & $<1$ & - \\
\hline & Medium & $7.3 \pm 1.7$ & + & $<1$ & - \\
\hline & POase & $11.4 \pm 2.1$ & + & $<1$ & - \\
\hline & $10^{-6}$ & $35.3 \pm 2.3$ & H & $<1$ & - \\
\hline & Medium & $51.4 \pm 2.0$ & $H \rightarrow H$ & $<1$ & - \\
\hline & POase & $62.1 \pm 1.5$ & HI & $<1$ & - \\
\hline & $10^{-5}$ & $42.7 \pm 2.1$ & $H-H$ & $<1$ & - \\
\hline & Medium & $65.8 \pm 1.2$ & HH & $<1$ & - \\
\hline & POase & $77.7 \pm 0.9$ & $H H+$ & $<1$ & - \\
\hline
\end{tabular}

untreated cells and RA-treated cells in the percentage of Fc receptor positive cells; $87.5 \%$ of the untreated cells possessed Fc receptors on day 4, while this percentage was $76.9 \%$ for $10^{-5} \mathrm{M}$ RA-treated THP-1-Cs 5 cells. However, the phagocytic capacity of the cells increased after treatment (Fig. 3c-d). Fig. 6 shows time course changes in phagocytosis mediated by the Fc receptor of THP-1-Cs5 cells after treatment with RA. With the addition of RA, the percentage of cells ingesting IgG-SRBC increased. After 4 days of incubation at $10^{-6} \mathrm{M}$ and $10^{-5} \mathrm{M}, 83.5 \%$ and $87 \%$ of the THP-1-Cs5 cells respectively were phagocytic. The values were $73.3 \%$ at $10^{-6} \mathrm{M}$ and $70.9 \%$ at $10^{-5} \mathrm{M}$ for THP-1-R cells (Fig. 7).

Fig. 7 shows the dose-response curves for the induction of phagocytic capacity by RA in both THP-1-Cs5 and THP-1-R cells after 2 and 4 days of culture. Both the percentage of phagocytic cells and the number of IgG-coated SRBC ingested in THP-1-Cs5 cells were remarkably enhanced as RA concentration increased. However, in THP-1-R cells, there was only a slight increase in the number of ingested particles after treatment with RA. In the absence of the inducer, the percentage of phagocytic cells in THP-1-Cs5 cells was $24.9 \%$, and the number of ingested particles was 197 per 100 phagocytes. However, the values increased to $89.5 \%$ and 913 particles in cells treated with $10^{-5} \mathrm{M}$ RA for 4 days.

RA-treated THP-1-Cs5 cells showed an increase in phagocytic activity of uncoated $\mathrm{SRBC}$ as shown in Fig. 6. Phagocytosis of uncoated SRBC by untreated THP-1-Cs5 

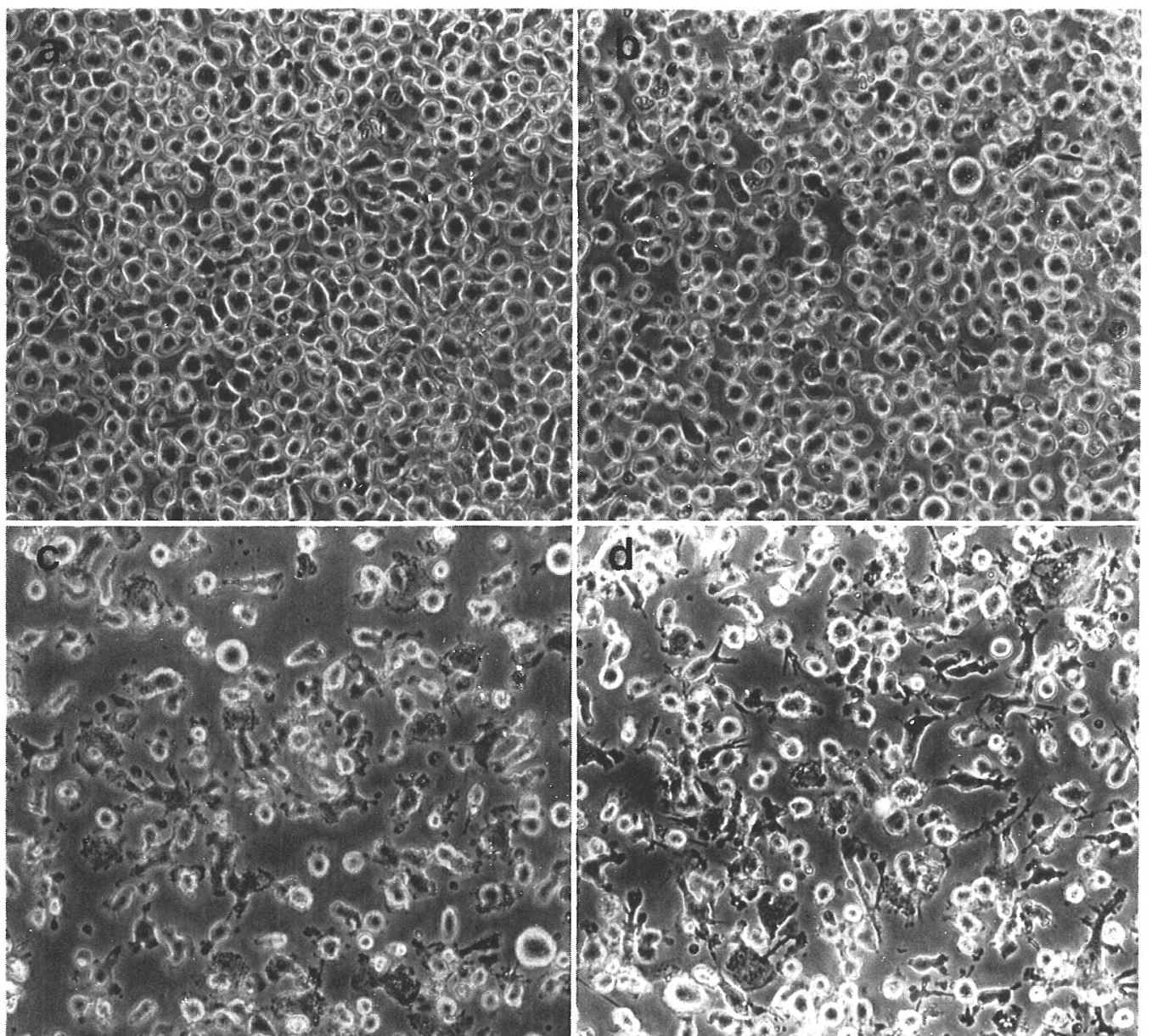

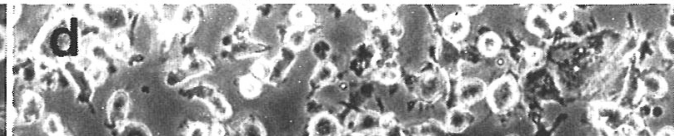

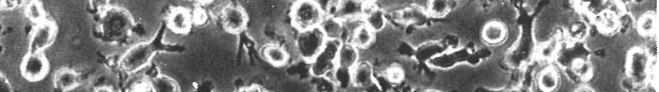

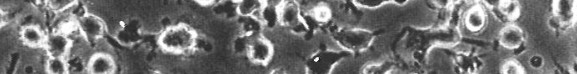

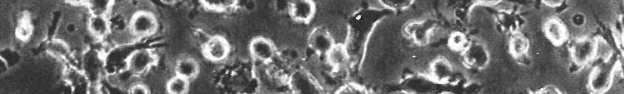

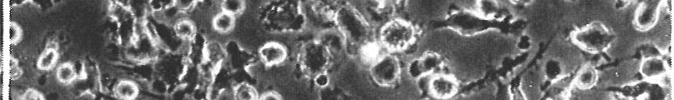

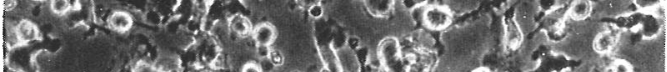

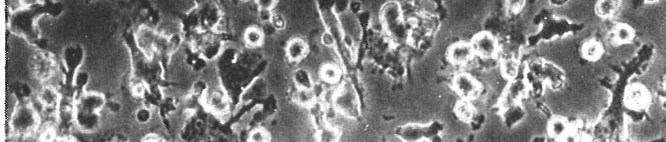

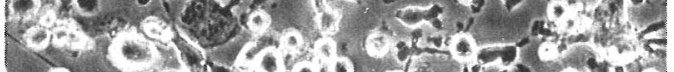

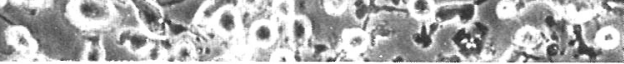

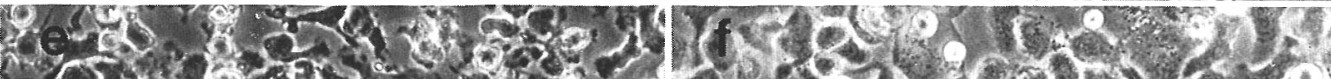
S.

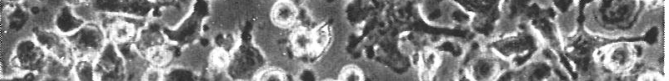

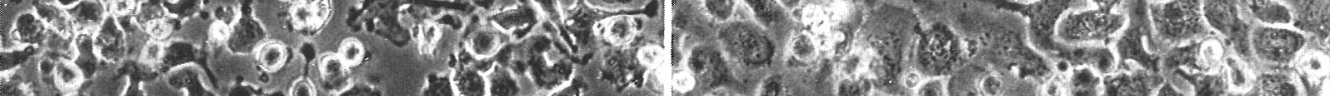

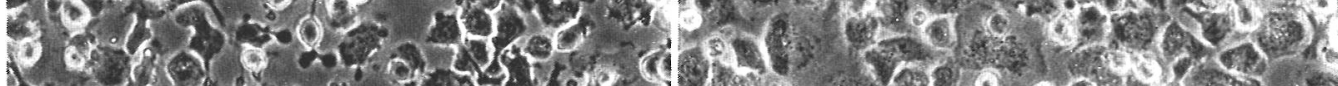

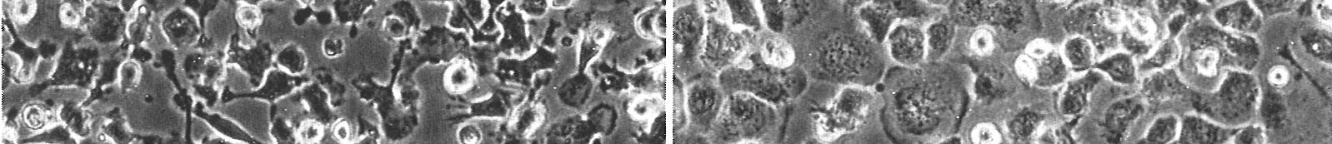

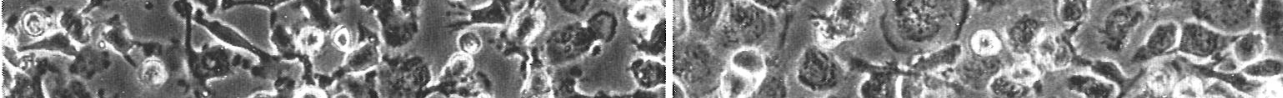

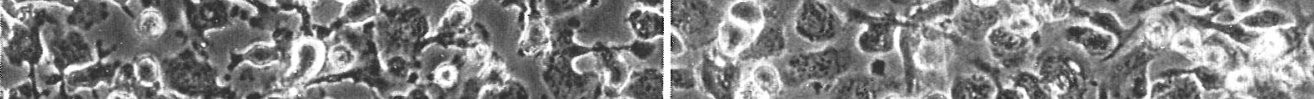

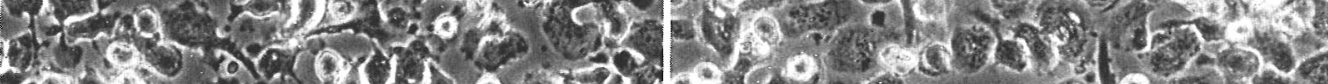

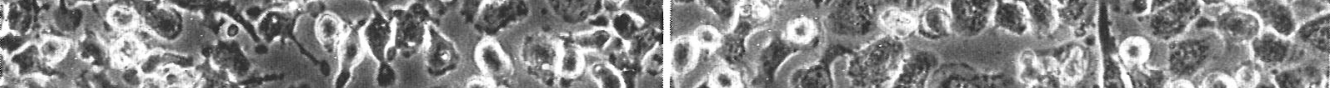

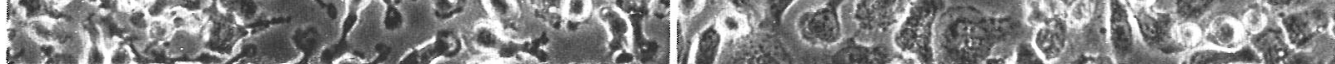




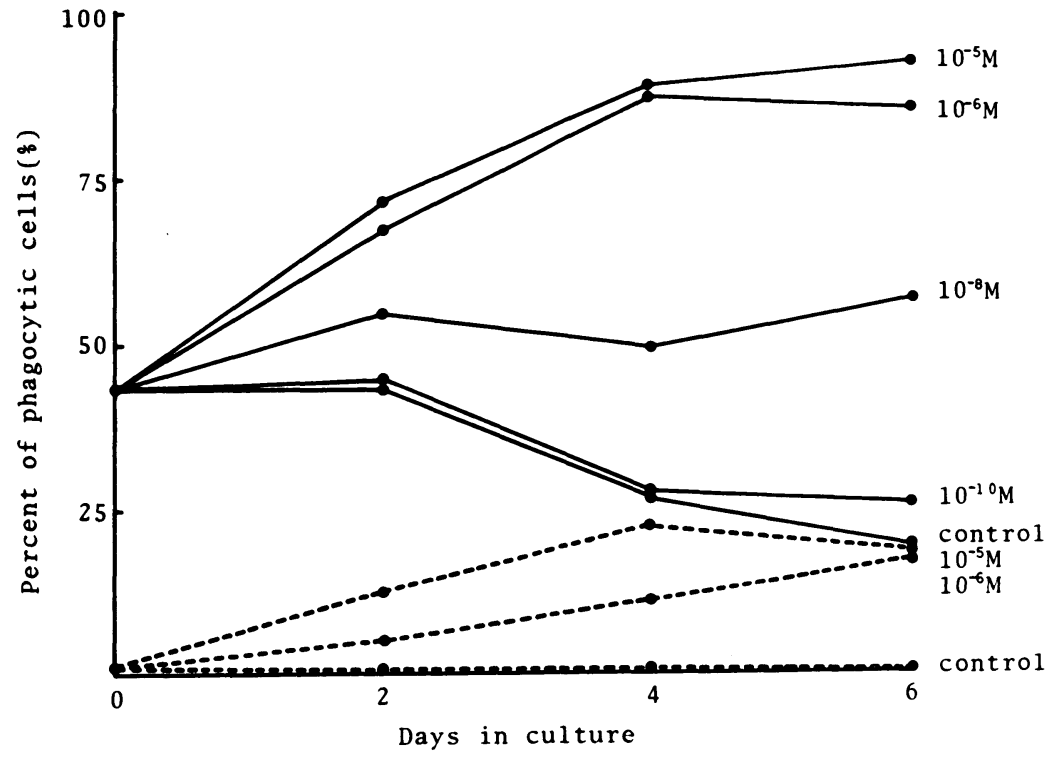

Fig. 6. Effects of retinoic acid on phagocytosis of SRBC and IgG-coated SRBC by THP-1-Cs5 cells. The values represent an average of 4 repeat experiments.

IgG-coated SRBC, uncoated SRBC.

cells was seen in $1.1 \%$ of the cells by day 4 . When exposed to $10^{-5} \mathrm{M}$ RA for 4 days, the phagocytic value increased to $22.8 \%$. Phagocytosis of uncoated SRBC by untreated THP-1-R cells on day 2 and on day 4 was seen in about $2 \%$ of the cells. After treatment with $10^{-10}$ to $10^{-5} \mathrm{M}$ RA, there was no significant increase in the percentage of cells which ingested SRBC; $10^{-7} \mathrm{M}$ RA-treated THP-1-R cells did not show a significant increase in phagocytotic activity over untreated cells. The maximum value for phagocytosis of uncoated SRBC by RA-treated cells never exceeded $5 \%$ (Fig. 7).

Effects of RA on the pinocytic activity of THP-1-Cs 5 cells and THP-1-R cells. The enhancement of pinocytic activity induced by RA was found to be much greater in THP-1-Cs5 cells than in THP-1-R cells. When untreated THP-1-Cs5 cells were exposed to $100 \mu \mathrm{g} / \mathrm{ml}$ of dextran sulfate for 2 days, the cells ingested little of the substance (Fig. 3e). After toluidine blue staining, the ingested substance appeared in the cytoplasm as tiny and indistinct purple granules. On the other hand, RA treated

Fig. 5. Phase contrast images of THP-1-Cs5 cells treated with or without RA for 4 days, followed by incubation for $2 \mathrm{~h}$ with RA-free fresh growth medium or fresh growth medium containing $1 \mathrm{mg} / \mathrm{ml}$ of HRP. $\times 175$

a: Untreated cells in the fresh growth medium.

b: Untreated cells in the fresh growth medium with HRP. No adherent cells were observed.

c: $10^{-5}$ M RA-treated cells. About a half of the cells adhered to the substratum and some of them showed spreading activity.

d: $10^{-6}$ M RA-treated cells in the fresh growth medium.

e: $10^{-5} \mathrm{M}$ RA-treated cells in the fresh growth medium. Note the many adherent and spreading cells and their processes.

f: $10^{-5} \mathrm{M}$ RA-treated cells in the fresh growth medium containing HRP. Thin, flat cells were found everywhere. 


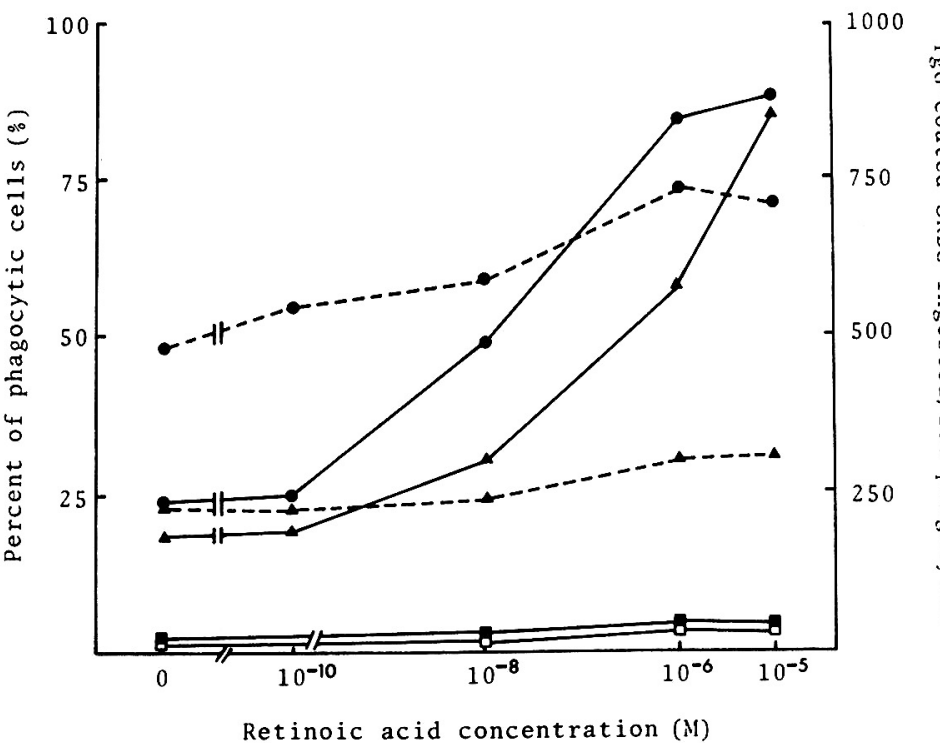

Fig. 7. Effects of various retinoic acid concentrations on the phagocytic capacity of THP-1-Cs5 and THP-1-R cells for IgG-coated SRBC, and on the phagocytic capacity of THP-1-R cells for uncoated SRBC. The values represent an average of 5 repeat experiments. The percent of phagocytic THP-1-Cs5 cells (-) and THP-1-R cells (-..) on day 4. The number of IgG-coated SRBC phagocytized by THP-1-Cs5 cells $(\mathbf{\Lambda} \mathbf{\Lambda})$ and THP-1-R cells $(\boldsymbol{\Lambda} \cdots \mathbf{\Delta})$ on day 4 . The percent of cells phagocytizing uncoated SRBC in THP-1-R cells on day $2(\square-\square)$ and on day $4(\square-\square)$.

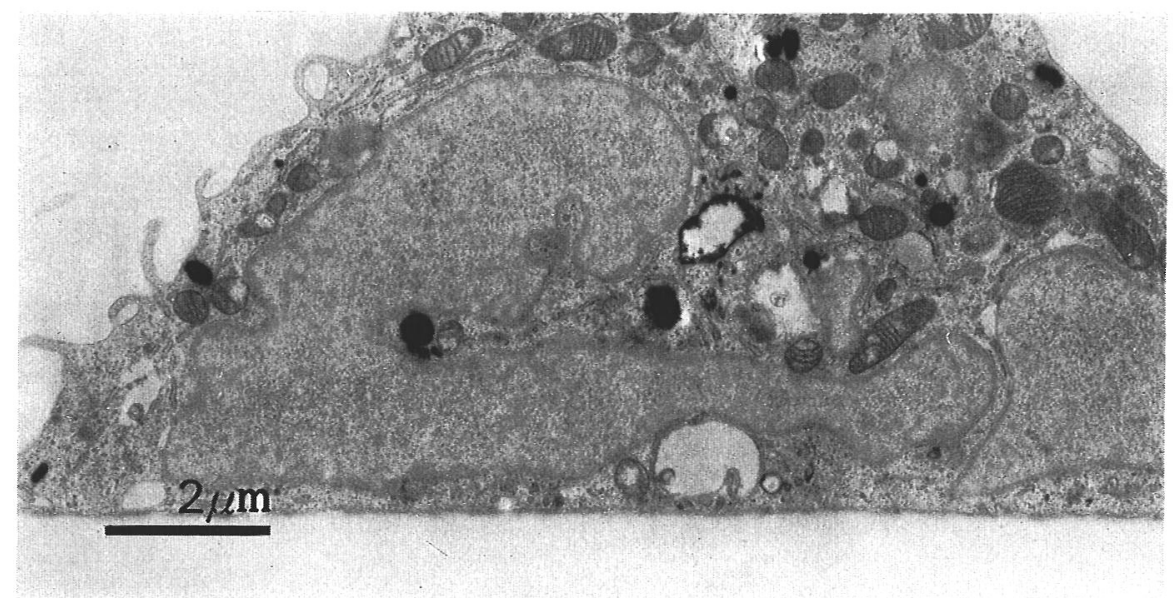

Fig. 8. Ultrastructural localization of HRP in RA-treated THP-1-Cs5 cells. Cells were treated with $10^{-5} \mathrm{M}$ RA for 4 days, followed by a $2 \mathrm{~h}$ incubation with RA-free fresh medium containing $1 \mathrm{mg} / \mathrm{ml}$ of HRP. The cells were treated to localize the regions of peroxidase activity and examined after staining with lead citrate. 
TABLE 2. EFFECTS OF VARIOUS RETINOIDS ON THE FUNCTIONAL DIFFERENTIATION OF THP-1-CS5 CELLS AFTER 4 DAYS OF CULTURE

Each value represents the mean \pm S.E. of 4 experiments

\begin{tabular}{|c|c|c|c|c|c|}
\hline \multirow{2}{*}{$\begin{array}{l}\text { Retinoids } \\
\left(10^{-5} \mathrm{M}\right)\end{array}$} & \multirow{2}{*}{$\begin{array}{c}\text { NBT } \\
\text { reduction } \\
(\%)\end{array}$} & \multicolumn{2}{|c|}{ phagocytosis } & \multirow{2}{*}{$\begin{array}{l}\text { Adherence } \\
(\%)\end{array}$} & \multirow{2}{*}{$\underset{(\%)}{\text { Cell }^{\mathrm{d}}}$} \\
\hline & & $\begin{array}{c}\text { Cells }^{\mathrm{a}} \\
(\%)\end{array}$ & $\mathrm{SRBC}^{\mathrm{b}}$ & & \\
\hline None & $3.3 \pm 0.8$ & $24.0 \pm 1.5$ & $2.0 \pm 0.1$ & $<1$ & 100 \\
\hline RA & $78.3 \pm 2.7$ & $89.6 \pm 1.5$ & $9.2 \pm 0.5$ & $67.8 \pm 2.7$ & $33.6 \pm 2.3$ \\
\hline R. acetate & $11.9 \pm 1.3$ & $46.9 \pm 1.8$ & $4.3 \pm 0.4$ & $18.8 \pm 3.0$ & $80.0 \pm 2.6$ \\
\hline Retinol & $12.2 \pm 0.6$ & $50.5 \pm 1.4$ & $4.3 \pm 0.4$ & $20.2 \pm 4.5$ & $77.1 \pm 4.7$ \\
\hline Retinal & $29.4 \pm 3.2$ & $64.1 \pm 1.3$ & $6.0 \pm 0.7$ & $41.6 \pm 5.4$ & $21.7 \pm 2.1$ \\
\hline
\end{tabular}

a Percentage of phagocytic cells.

b Number of SRBC per phagocyte.

c Percentage of adherent cells examined after incubation with retinoid-free fresh growth medium for $2 \mathrm{~h}$.

d Percentage of control.

e Retinyl acetate.

THP-1-Cs5 cells actively ingested the substance. The ingested material was located diffusely in the cytoplasm, and also appeared as numerous, larger, and more distinct granules (Fig. 3f).

Almost all of the THP-1-Cs5 cells incubated in the absence of HRP showed no peroxidase staining. After RA-treated cells were incubated with HRP, the enzyme was found in the perinuclear area.

In an electron micrograph, the majority of the ingested HRP appeared as membrane bound, electron dense granules, or as larger vacuoles containing only a peripheral rim of staining (Fig. 8).

Effects of $R A$ on the capacity of THP-1-Cs5 and THP-1-R cells to reduce NBT dye. Untreated THP-1-Cs5 cells had little capacity NBT dye (Table 2). When the cells were cultured with $10^{-5} \mathrm{M}$ RA for 4 days, the percentage of the cells with a strong capacity to reduce NBT dye reached a maximum of $78.3 \%$ (Table 2). There was no significant induction of this ability during 6 days of culture at a concentration of $10^{-10} \mathrm{M}$ RA. The reducing activity of RA-treated THP-1-R cells also increased to the same extent as that of RA-treated THP-1-Cs5 cells.

Effects of various retinoids on the functional differentiation of THP-1-Cs5 cells. The effects of various other retinoids on inducing the activities already discussed were examined in THP-1-Cs5 cells (Table 2). Among these retinoids, retinoic acid induced the greatest increases in the following functional activities: phagocytic activity, NBT reducing activity and the activity of adhering to the substrate.

\section{DISCUSSION}

Retinoic acid (RA) has been known to induce the differentiation of murine teratocarcinoma cells and several human leukemic cell lines $(2,11,13,21,31)$. We undertook a study of cell differentiation induced by RA in two THP-1 cell lines with different chromosome numbers. We also studied cell differentiation in THP-1-Cs5 cells induced by several other retinoids.

In terms of function and morphology, RA caused THP-1-Cs5 cells to become 
more mature. First, THP-1-Cs5 cells treated with RA acquired the capacity to adhere to the substratum and to spread. It has been reported that a human histiocytic lymphoma cell line, U-937, and a human monocytic leukemia cell line, THP-1, treated with RA acquired little capacity to adhere $(11,21)$. There are few reports about the induction by treatment with RA of the spreading capacity on established monocytic leukemia cells. We examined the effects of RA on the induction of adherence in THP-1-R cells, but did not find a significant increase in the capacity to adhere (Table 1). In contrast, THP-1-Cs5 cells treated with RA acquired the capacity to adhere and spread, and the capacity to adhere and spread were enhanced by then incubating the cells in RA-free fresh medium or fresh medium with HRP (Table 1, Fig. 5). The cells acquired a macrophage-like morphology.

It is well known that monocytes which are seeded on culture dishes rapidly adhere to the growth substratum and differentiate into a heterogenous population consisting of fusiform types and epithelioid types (41). RA-treated THP-1-Cs5 cells normally were fusiform. On the other hand, after exposure to HRP, there was an increase in the number of the cells showing a more flattened, epithelioid-like form. Mechanisms for the enhancement of adhering and spreading activities by HRP are unknown at present.

An extracellular matrix must be present and a reorganization of the cellular cytoskeletal components is necessary be for cell adherence and spreading can occur $(5,14,17)$. Lehto et al. reported an extensive cytoskeletal reorganization during the monocyte-macrophage transition in culture (17). They suggested that the reorganization of actin and vinculin was necessary for the initial attachment stage, and that the reorganization of vimentin filaments and microtubules was necessary for cell flattening.

RA-treated THP-1-R cells did not acquire the capacity to adhere and spread even after being incubated in fresh growth medium or fresh growth medium containing HRP (Table 1). These results suggest that there may be defects in the organization of the cytoskeletal components in RA-treated THP-1-R cells.

After treatment with RA, the proportion of the two THP-1 cell lines which phagocytosed IgG-coated SRBC was found to have increased (Fig. 6, 7). Furthermore, there was a remarkable increase in the number of SRBC ingested by RA-treated THP1-Cs5 cells (Fig. 7). More than $80 \%$ of the THP-1-Cs 5 cells incubated without RA possessed Fc-receptors, and most cells had more than $10 \mathrm{IgG}-\mathrm{SRBC}$ at their surface. However, the number of IgG-SRBC ingested per phagocyte was small. After exposure to RA, the number of particles ingested per phagocyte increased by about 5 times. These results suggest that RA converts THP-1-Cs 5 cells into avidly phagocytic cells. On the other hand, there was little increase in the number of IgG-SRBC ingested per 100 phagocytes in the RA-treated THP-1-R cells (Fig. 7).

There was no noticeable difference between the number of the SRBC attached to the RA-treated THP-1-Cs5 and THP-1-R cell surfaces. Therefore, the results also suggest that RA-treated THP-1-Cs5 cells have a more avid phagocytic activity than RA-treated THP-1-R cells.

Tsuchiya et al. reported that THP-1-O and THP-1-R cells acquired the capacity to phagocytose uncoated SRBC after treatment with TPA (37). On the other hand, RA could only poorly induce THP-1-Cells to ingest uncoated SRBC (11). These findings are consistent with our present data. However, THP-1-Cs5 cells, a cloned variant of THP-1-Cells, acquired a strong capacity to phagocytose SRBC (Fig. 6, 7). 
In our comparative studies on the induction by RA of cell differentiation in two THP-1 cell lines with different chromosome numbers, the most remarkable functional differences found between the two RA-treated THP-1 cell lines were in the activity of adhering and spreading, and in the ability to phagocytose uncoated-SRBC. However, there is no explanation for the remarkable difference seen in the effect of RA on the two cell lines at the present time, except for the difference in chromosome numbers. A more biochemical investigation of the mechanisms of cell differentiation will be attempted in the future.

Soluble peroxidase is an example of a molecule internalized by fluid-phase pinocytosis (7). In contrast, dextran sulfate is a highly negatively charged molecule which binds to the plasma membrane of cells and is internalized by adsorptive pinocytosis $(3,7)$. Mouse and human mononuclear phagocytes actively ingest the substance. Unlike mononuclear phagocytes, granulocytes and lymphocytes do not ingest the substance $(8,38)$. Remarkably, our results show that ingestion of dextran sulfate occurs in RA-treated THP-1-Cs5 cells (Fig. 3f).

The cytoskeletal system (microfilaments, microtubules and intermediate filaments) has an important role in the phagocytic and pinocytic processes of mononuclear phagocytes $(22,23,24,27,33,34)$. Furthermore, fibronectin is reported to be one of the substances which enhance Fc-receptor mediated SRBC phagocytosis (25).

THP-1-Cs5 and THP-1-R cells should be useful materials in the investigation of the relationships between these substances and phagocytic activity.

RA-treatment of THP-1-Cs5 and THP-1-R cells enhanced the capacity of the cells to reduce NBT by the same amount. After treatment with RA, there was a remarkable increase in the acid phosphatase activity of THP-1-Cs5 cells. These results may indicate that the RA-treated cells acquire a strong ability to process foreign particles or substances.

There have been several reports on the ultrastructural changes which occur in mouse or human leukemic cells when they are induced to differentiate into monocytesmacrophages-like cells by inducing agents $(12,30,37)$. We investigated the ultrastructural changes that occur in THP-1-Cs 5 cells after treatment with RA. RA-treated cells had fewer free ribosomes, a moderate development of the Golgi apparatus, and more mitochondria and pinocytic vesicles as well as a remarkable increase in the number of lysosomes (Fig. 4C). These results may indicate that the RA-treated THP-1-Cs5 cells have also been ultrastructurally converted into a more mature form.

Of all the retinoids tested, retinoic acid caused the most remarkable differentiation of the THP-1-Cs5 cells (Table 2). The results agree with findings from other neoplastic cell lines $(2,13,31)$. In contrast, retinal produced almost the same inhibition in cell growth as RA, but its ability to induce differentiation of THP-1-Cs5 cells was less than that with RA.

These results indicate that THP-1-Cs5 cells which contain aneuploid chromosomes should turn out to be a better model for RA-induced differentiation than THP-1-R cells which contain diploid chromosomes. The present data also suggest that both THP-1 cell lines should be useful models in the investigation of the mechanisms by which adherence and spreading, pinocytosis and receptor-mediated immune phagocytosis occur.

Acknowledgments. The author wishes to express his thanks to Prof. T. Kimoto, Department of Pathology, Kawasaki Medical School, for his valuable advice and encouragement. Also, thanks are due to Mr. Kenzo Uehira and Taiji Suda for their kind advice in the electron microscopy. 
This research was supported partly by Kawasaki Medical School under the project research grant 60-101.

\section{REFERENCES}

1. BARKa, T. and R.J. Anderson. Histochemical methods for acid phosphatase using hexazonium pararosaniline as coupler. J. Histochem. Cytochem. 10, 741-753, 1962

2. Breitman, T.R., S.E. Selonick and S.J. Collins. Induction of differentiation of the human promyelocytic leukemia cell line (HL-60) by retinoic acid. Proc. Natl. Acad. Sci. U.S.A. 77, 2936-2940, 1980

3. CoHN, Z.A. and E. PARks. The regulation of pinocytosis in mouse macrophages II. Factors inducing vesicle formation. J. Exp. Med. 125, 213-232, 1967

4. Collins, S.J., A. Bondner, R. Ting and R.C. Gallo. Induction of morphological and functional differentiation of human promyelocytic leukemia cells (HL-60) by compounds which induce differentiation of murine leukemia cells. Int. J. Cancer 25, 213-218, 1980

5. Fridman, R., Y. Alon, F. Dolzanski, Z. Fuks and I. Vlodavsky. Cell interaction with the extracellular matrices produced by endothelial cells and fibroblasts. Exp. Cell Res. 158, 461476, 1985

6. Gaffney, E.V., S.C. Tsai, M.L. Dellaquila and S.E. Ligenfelter. Production of growthinhibitory activity in serum-free medium by human monocytic leukemia cells. Cancer Res. 43, 3668-3673, 1983

7. Gordon, S. and Z.A. CoHN. The macrophage. Int. Rev. Cytol. 36, 171-214, 1973

8. Gould, Th.J.L.M., C. SChOtTE and R. VAN FurTh. Identification and characterization of the monoblast in mononuclear phagocyte colonies growth in vitro. J. Exp. Med. 142, 11801199, 1975

9. Graham, R.C., JR. and M.J. Karnovsky. The early stages of absorption of injected horseradish peroxidase in the proximal tubules of mouse kidney: Ultrastructural cytochemistry by a new technique. J. Histochem. Cytochem. 14, 291-302, 1966

10. HARris, P. and P. RALPH. Human leukemic models of myelomonocytic development: A review of the HL-60 and U-937 cell lines. J. Leukocyte Biol. 37, 407-422, 1985

11. Hemmi, H. and T.R. Breitman. Induction of functional differentiation of a human monocytic leukemia cell line (THP-1) by retinoic acid and cholera toxin. Jpn. J. Cancer Res. (Gann) 76, 345-351, 1985

12. Hirai, K., K. Nagata, M. Maeda and Y. Ichikawa. Changes in ultrastructures and enzyme activities during differentiation of myeloid leukemia cells to normal macrophages. Exp. Cell Res. 124, 269-283, 1979

13. Honma, Y., K. Takenaga, T. Kasukabe and M. Hozumi. Induction of differentiation of cultured human promyelocytic leukemia cells by retinoids. Biochem. Biophys. Res. Commun. 95, 507-512, 1980

14. Hovi, T., V-P. Lehto and I. ViRTANen. Interferon affects the formation of adhension plagues in human monocyte cultures. Exp. Cell Res. 159, 305-312, 1985

15. Нуодон, F. and T. Кімото. Induction of functional differentiation of human monocytic leukemia cell line (THP-1). 3rd International Congress on Cell Biology Aug. 26-31, p. 422 (Abstr. 3255), 1984, The Japan Society for Cell Biology, Tokyo.

16. KaPlan, G. and B. MoRland. Properties of a murine monocytic tumor cell line J-774 in vitro I. Morphology and endocytosis. Exp. Cell Res. 115, 53-61, 1978

17. Lehto, V-P., T. Hovi, T. Vartio, R.A. Badley and I. Virtanen. Reorganization of cytoskeletal and contractile elements during transition of human monocytes into adherent macrophages. Lab. Invest. 47, 391-399, 1982

18. LI, C.Y., K.W. LAM and L.T. YAM. Esterase in human leukocytes. J. Histochem. Cytochem. 21, 1-12, 1973

19. Luft, J.H. Improvements in epoxy resin embedding methods. J. Biophys. Biochem. Cytol, 9, 409-414, 1961 
20. Nillson, K., K. Forsbeck, M. Gidlund, C. Sundstrom, T. Totterman, J. Sallstrom and P. VENGE. Surface characteristics of the U-937 human histiocytic lymphoma cell line: Specific changes during inducible morphologic and functional differentiation in vitro. Haematology and Blood Transfusion 26, 215-221, 1981

21. OlsSON, I.L. and T.R. BREITMAN. Induction of differentiation of human histiocytic lymphoma cell line U-937 by retinoic acid and cyclic adenosine 3' :5' monophosphate-inducing agents. Cancer Res. 42, 3924-3927, 1982

22. Painter, R.G. and A.T. MClntosh. The regional association of actin and myosin with sites of particle phagocytosis. J. Supramol. Struct. 12, 369-384, 1979

23. Phaire-Washington, L., E. Wang and S.C. Silverstein. Phorbol myristate acetate stimulates pinocytosis and membrane spreading in mouse peritoneal macrophages. J. Cell Biol. 86, 634640,1980

24. Phaire-Washington, L., S.C. Silverstein and E. Wang. Phorbol myristate acetate stimulates microtubule and $10 \mathrm{~nm}$ filament extension and lysosome redistribution in mouse macrophages. J. Cell Biol. 86, 641-655, 1980

25. Pommier, C.G., S. Inada, L.F. Fries, T. Takahashi, M.M. Frank and E.J. Brown. Plasma fibronectin enhances phagocytosis of opsonized particles by human peripheral blood monocytes. J. Exp. Med. 157, 1844-1854, 1983

26. Ralph, P., P.E. Harris, C.J. Punjabi, K. Welte, P.B. Litcofsky, M.-K. Ho, B.Y. Rubin, M.A.S. Moore and T.A. SPRINGer. Lymphokine inducing terminal differentiation of the human monoblast leukemia line U937: A role for $\gamma$ interferon. Blood 62, 1169-1175, 1983

27. Reaven, E.P. and S.G. Axline. Subplasmalemmal microfilaments and microtubules in resting and phagocytizing cultivated macrophages. J. Cell Biol. 59, 12-27, 1973

28. ReYNOLds, E.S. The use of lead citrate at high $\mathrm{pH}$ as an electron-opaque stain in electron microscopy. J. Cell Biol. 17, 208-212, 1963

29. Roels, F., E. Wisse, B. De Prest and J. Van Der Meulen. Cytochemical discrimination between catalases and peroxidases using diaminobenzidine. Histochemistry 41, 281-312, 1975

30. Rovera, G., D. SAntoli and C. Damsky. Human promyelocytic leukemia cell in culture differentiate into macrophage-like cells when treated with a phorbol ester. Proc. Natl. Acad. Sci. U.S.A. 76, 2779-2783, 1979

31. Sporn, M.B. and A.B. Robert. Role of retinoids in differentiation and carcinogenesis. Cancer Res. 43, 3034-3040, 1983

32. Steinman, R.M. and Z.A. Cohn. The interaction of soluble horseradish peroxidase with mouse peritoneal macrophages in vitro. J. Cell Biol. 55, 186-204, 1972

33. Stendahl, O.I., J.H. Hartwig, E.A. Brotschi and T.P. Stossel. Distribution of actinbinding protein and myosin in macrophages during spreading and phagocytosis. J. Cell Biol. 84, 215-224, 1980

34. Stossel, T.P. Contractile proteins in phagocytosis: An example of cell surface-to-cytoplasm communication. Fed. Proc. 36, 2181-2184, 1977

35. Sundstrom, C. and K. Nilsson. Establishment and characterization of a human histiocytic lymphoma cell line (U-937). Int. J. Cancer 17, 565-577, 1976

36. Tsuchiya, S., M. Yamabe, Y. Yamaguchi, Y. Kobayashi, T. Konno and K. Tada. Establishment and characterization of a human acute monocytic leukemia cell line (THP-1). Int. J. Cancer 26, 171-176, 1980

37. Tsuchiya, S., T. Kobayashi, Y. Goto, H. Okumura, S. NaKae, T. Konno and K. Tada. Induction of maturation in cultured human monocytic leukemia cells by a phorbol diester. Cancer Res. 42, 1530-1536, 1982

38. VAN Furth, R., J.A. RAEBURN and T.L. VAN Zwet. Characteristics of human mononuclear phagocytes. Blood 54, 485-500, 1979

39. Willcox, M.B., D.W. Golde and M.J. Cline. Cytochemical reactions of human hematopoietic cells in liquid culture. J. Histochem. Cytochem. 24, 979-983, 1976

40. YAM, L.T., C.Y. LI and W.H. CROSBY. Cytochemical identification of monocytes and granulocytes. J. Clin. Pathol. 55, 283-290, 1971 
41. Zuckerman, S.H., S.K. ACKerman and S.D. Douglas. Long-term human peripheral blood monocyte cultures: Establishment, metabolism and morphology of primary human monocytemacrophage cell cultures. Immunology 38, 401-411, 1979

(Received for publication, March 2, 1987) 